2017-07-17

\title{
The Impact of Power Curve Estimation on Commercial Wind Power Forecasts - An Empirical Analysis
}

\author{
Gianni Goretti \\ Technological University Dublin, d15123939@mytudublin.ie \\ Aidan Duffy \\ Technological University Dublin, aidan.duffy@tudublin.ie \\ Tek Tjing Lie \\ Auckland University of Technology
}

Follow this and additional works at: https://arrow.tudublin.ie/engschcivcon

Part of the Civil Engineering Commons, Energy Systems Commons, and the Power and Energy

Commons

\section{Recommended Citation}

G. Goretti, A. Duffy, and T. T. Lie, (2017) "The impact of power curve estimation on commercial wind power forecasts An empirical analysis," International Conference on the European Energy Market, EEM, 2017.

This Conference Paper is brought to you for free and open access by the School of Civil and Structural Engineering at ARROW@TU Dublin. It has been accepted for inclusion in Conference papers by an authorized administrator of ARROW@TU Dublin. For more information, please contact arrow.admin@tudublin.ie, aisling.coyne@tudublin.ie,gerard.connolly@tudublin.ie.

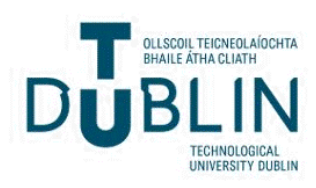




\section{The Impact of Power Curve Estimation on Commercial Wind Power Forecasts - An Empirical Analysis}

\author{
Gianni Goretti \\ School of Civil and \\ Structural Engineering \\ Dublin Institute of Technology \\ Dublin, Ireland \\ Email: gianni.goretti@mydit.ie
}

\author{
Aidan Duffy \\ School of Civil and \\ Structural Engineering \\ Dublin Institute of Technology \\ Dublin Ireland \\ Email: aidan.duffy@dit.ie
}

\author{
Tek Tjing Lie \\ School of Engineering, Computer \\ and Mathematical Sciences \\ Auckland University of Technology \\ Auckland, New Zealand
}

\begin{abstract}
An increasing number of utilities participating in the energy market require short term (i.e. up to 48 hours) power forecasts for renewable generation in order to optimize technical and financial performances. As a result, a large number of forecast providers now operate in the marketplace, each using different methods and offering a wide range of services. This paper assesses five different day-ahead wind power forecasts generated by various service providers currently operating in the market, and compares their performance against the stateof-the-art of short-term wind power forecasting. The work focuses on how power curve estimations can introduce systematic errors that affect overall forecast performance. The results of the study highlight the importance of: accurately modelling the wind speedto-power output relationships at higher wind speeds; taking account of power curve trends when training models; and the need to incorporate long-term (months to years) power curve variability into the forecast updating process.
\end{abstract}

Index Terms - wind power forecast; wind turbine power curve; short-term forecasting; forecast assessment; wind energy.

\section{INTRODUCTION}

Numerous wind power forecast providers currently operate in the European marketplace, each of them offering different forecast products. However, there is relatively little literature reporting the extent to which these accurately predict power output, where error arises in the forecasting process and to what extent industry best practice reflects the research state-ofthe-art. This study evaluates the performance of five different day-ahead wind power forecasts generated by various service providers.

The main error in a short-term forecasting model generally stems from the Numerical Weather Prediction (NWP) component of the forecasting process and, consequently, recent research has concentrated on improving the accuracy of these models. However, the conversion of meteorological data to power can also significantly influence overall forecast performance. This study focuses on how the estimation of the power curve by commercial forecasters can affect the uncertainty already present in the wind speed forecast.
The remainder of the paper is presented as follows. Section II reviews the state-of-the-art of short-term wind power forecasting and the methods used for modelling wind farm power production. Section III describes the data and the case studies investigated. The methodology is described in Section IV. Results are presented in Section V and discussed in Section VI. Conclusions are finally presented in Section VII.

\section{LITERATURE REVIEW}

In the recent years, a number of studies have assessed the performances of short-term wind power forecasts that are representative of the state-of-the-art. In [1], several models were tested on a number of test cases having different terrain complexity; the paper presents guidelines on assessing model performance and gives an overview on what power forecast performances can be expected as a function of site characteristics. For example, results for wind farms located in complex terrain show a stable behaviour of the normalised mean absolute error (NMAE, later defined in Section IV-A), with little increase of the errors with forecast horizon; $N M A E$ values are lower for wind farms located in flat terrain and there is very low dispersion of the values for different prediction models.

A comprehensive picture of the state-of-the-art of short-term wind power forecasting is presented in [2]. The article presents the results of a benchmarking exercise: a range of modelling approaches was evaluated using two different test cases over a time horizon ranging from 0 to 72 hours and 0 to 48 hours. The results provide recent reference values that can be used to compare the performance of current wind power forecasts. For the 0-72 hour ahead forecast, the values of the NMAE over the whole forecast ranged between $9.0 \%$ and $20.8 \%$. For the $0-48$ hour ahead forecast, the NMAE values range between $9.5 \%$ and $22.8 \%$.

The prediction horizons for day-ahead wind power forecasts are driven by electricity market and system needs and usually vary from 12 to 36 hours. Within this time horizon the 
best performances are usually obtained by prediction models involving the use of NWP forecasts [3]. Typically in these cases, the generation of a wind power forecast for a wind farm consists of (at least) the following two steps:

- wind speed and direction forecast data are generated using a NWP model; and

- these are converted to electric power forecasts using either a deterministic or probabilistic power curve function [4], or power model.

Different types of power models can be employed to convert wind speed to power for a wind farm [5]. The basic model is based on the turbine manufacturer's power curve multiplied by the number of turbines. Advanced models may involve a number of approaches including: the correction of air density using temperature and pressure data from the NWP forecast; the use of software for site specific flow/wake modelling (in the absence of historical measured data); or the use of historical measured data to derive an empirical power model (the preferred option).

\section{CASE Studies}

Detailed data were obtained for two onshore wind farms in norther Europe with nominal installed capacities of $30 \mathrm{MW}$ (Wind Farm 1) and 5 MW (Wind Farm 2). Both are located in complex terrain and are subject to similar climatic conditions.

Models were trained by commercial forecast providers using up to four years of output data which were then tested over a period of four months in 2015. Each forecast (A, B, C, D, and E) comprised a one day-ahead deterministic forecast of power output for each wind farm at half-hourly time intervals. The performances of the wind and power forecasts were assessed against wind speeds and power outputs measured at each of the sites over the test period, as described in Section IV.

\section{Methodology}

\section{A. Error Measures}

In this study, forecast error is defined as: $e_{i}=\hat{y}_{i}-y_{i}$, where $\hat{y}_{i}$ is the forecast quantity, and $y_{i}$ is the measured quantity.

The performances of the power forecasts were assessed by employing the widely-used verification framework described in [6]. The numerical descriptive measures employed are:

- Bias: Bias $=\frac{1}{N} \sum_{i=1}^{N} e_{i}$.

- Mean Absolute Error: $M A E=\frac{1}{N} \sum_{i=1}^{N}\left|e_{i}\right|$.

- Root Mean Square Error: $R M S E=\sqrt{\frac{1}{N} \sum_{i=1}^{N} e_{i}^{2}}$.

They were computed over the whole evaluation period, and were normalised by wind farm installed capacity, $P_{n}$.

The same error measures were also characterised by wind speed, e.g. the bias of power forecast at wind speed $v_{k}$ is:

$$
\operatorname{Bias}\left(v_{k}\right)=\sum_{i=1}^{N} \frac{\hat{P}\left(v_{i}\right)-P\left(v_{i}\right)}{N} \mid v_{i} \in\left[v_{k}-0.5, v_{k}+0.5[\right.
$$

\section{B. Power Modelling}

We assume that forecasters used historical (i.e. from the training data set) measured power production data to derive a site-specific power model which they used to convert their wind speed forecast into power. To visualise the relationship between wind speed and power output (either measured or forecast), we grouped power values into $1 \mathrm{~m} / \mathrm{s}$ wind speed bins, so that $\left\{P\left(v_{i}\right) \in \mathcal{A}_{k} \mid v_{k}-0.5 \leq v_{i}<v_{k}+0.5\right\}$; we then plotted each set $A_{k}$ against the wind speed $v_{k}$ using a box-andwhisker plot. An example of such a graph is shown in Fig. 1: here, the boxplots of actual generation are plotted together with the measured values and the manufacturer's power curve.

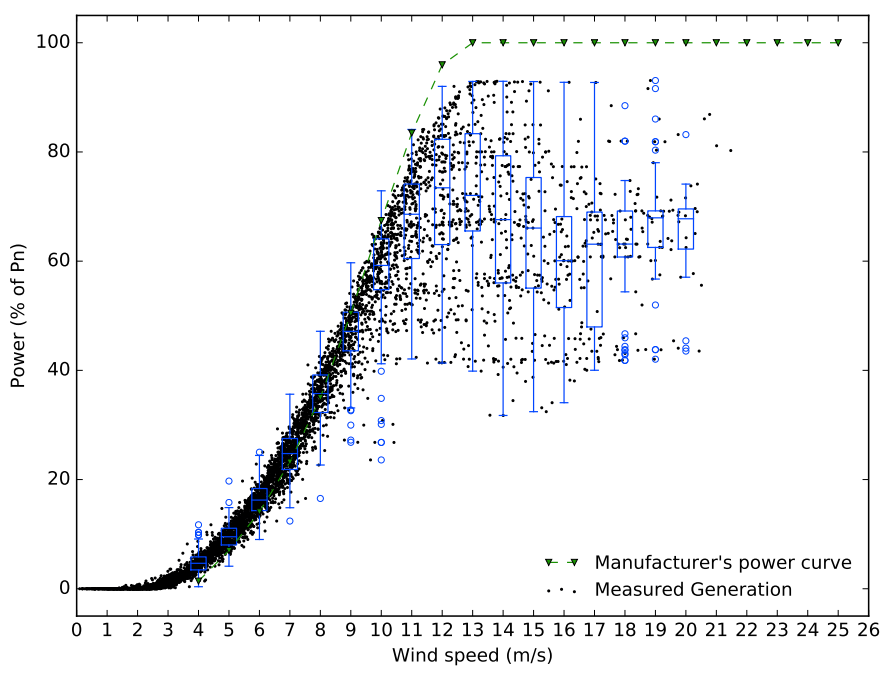

Fig. 1. Box-and-whisker plots (blue) of actual generation during the test period for Wind Farm 1

The resulting graph can then be interpreted as an empirical probabilistic power curve for the site. In fact, one can analyse how a forecaster converted the predicted wind speed into power - i.e. estimate the forecaster's power curve model - by building the same type of graph with forecast values. This also allows us to compare the forecaster's model with the actual distribution of power. Results of this analysis is discussed in Section V.

\section{RESUlts}

\section{A. Forecast Assessment}

Both wind farms showed a high variability of possible power outputs for a single wind speed value, while actual power outputs often differed from those predicted by the manufacturer's power curve, as Fig. 1 clearly shows. The same figure interestingly shows that Wind Farm 1 never achieves nominal power output; this was also consistently observed during the training period.

Scatter plots of the five forecasts against measured values for Wind Farm 1 are presented in Fig. 2 which show the degree of correlation between forecast and measured power values. It can be observed that the forecasts never predicted power outputs higher than $95 \%$ of $P_{n}$. Since the providers were 


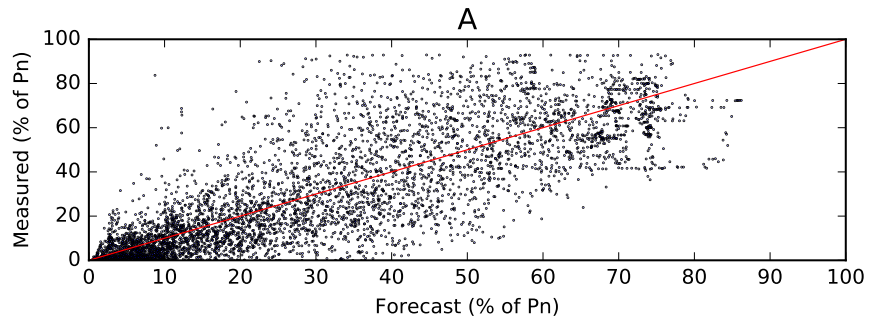

B

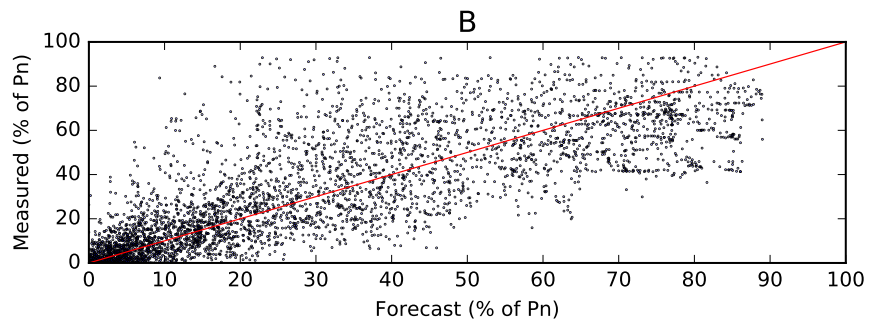

C
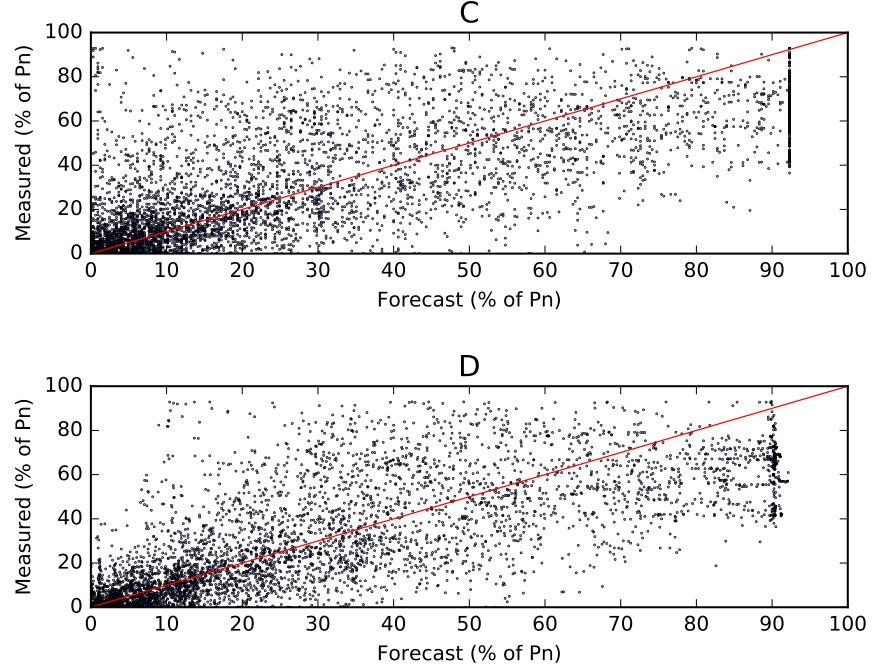

$\mathrm{E}$

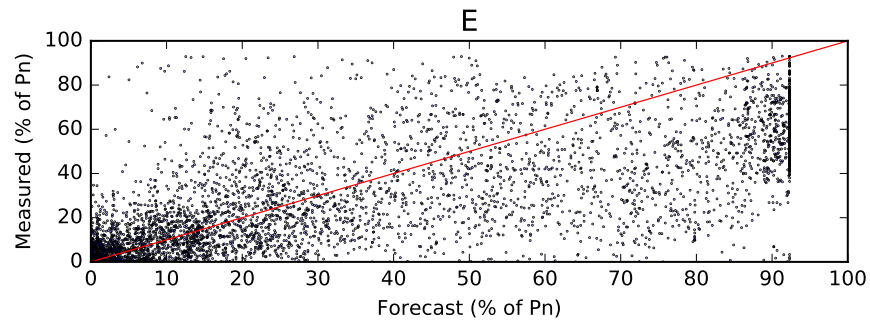

Fig. 2. Scatter plots of power forecasts against measured values for Wind Farm 1

not updated with real data during the trial period, this means that they did use historical measured data to train their power models, in accordance with the assumption in Section IV-B.

The statistical parameters presented in Section IV-A were computed for each forecaster over the test period. Results for both wind farms are presented in Table I.

\section{B. Power Modelling}

In Fig. 3, the power curve model adopted by provider B at Wind Farm 1 is compared to the actual distribution of power
TABLE I

ERROR MEASURES NORMALISED AS PERCENTAGE OF WIND FARM NAMEPLATE CAPACITY $\left(P_{n}\right)$.

\begin{tabular}{llllll}
\hline Wind Farm 1 & A & B & C & D & E \\
\hline NBIAS & 0.5 & 0.4 & -0.2 & 0.6 & 7.3 \\
MAE & 10.4 & 10.6 & 13.7 & 12.5 & 16.3 \\
RMSE & 14.6 & 15.4 & 20.0 & 18.1 & 23.3 \\
\hline Wind Farm 2 & A & B & C & D & E \\
\hline NBIAS & -2.7 & 4.3 & 4.3 & -9.5 & -9.4 \\
MAE & 14.5 & 11.8 & 13.2 & 17.7 & 18.5 \\
RMSE & 20.7 & 17.1 & 19.4 & 25.8 & 27.0 \\
\hline
\end{tabular}

during the test period. The boxplots are constructed according to the procedure described in Section IV-B.

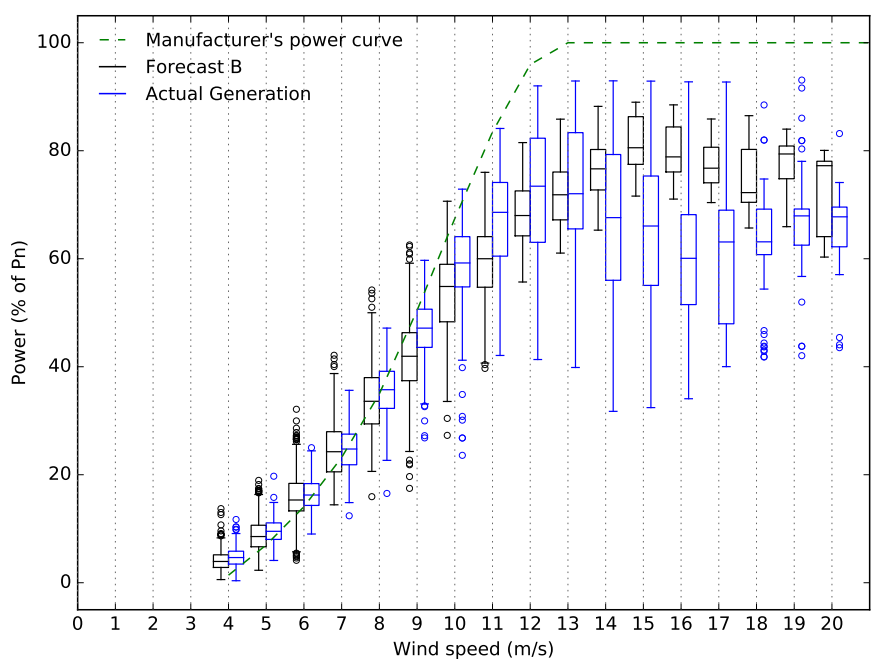

Fig. 3. Box-and-whisker plots of forecast B and of measured generation for Wind Farm 1

From the figure, it can be observed that forecaster B:

- achieved good power conversion accuracies at low wind speeds $(v \leq 8 \mathrm{~m} / \mathrm{s})$;

- slightly underestimated power in the range $9 \mathrm{~m} / \mathrm{s} \leq$ $v \leq 11 \mathrm{~m} / \mathrm{s}$; and

- overestimated power at high wind speeds $(v \geq 15 \mathrm{~m} / \mathrm{s})$.

Fig. 4 shows the bias of the wind speed and power forecasts generated by B, grouped into wind speed bins (see Section IV-A). While the wind speed forecast is, in general, negatively biased, the power forecast bias shows a different pattern, going from negative to positive at $v=14 \mathrm{~m} / \mathrm{s}$ and remaining positive at higher wind speeds. The reason for this behaviour must be a significant positive bias introduced by B in the conversion of high wind speed into power. 

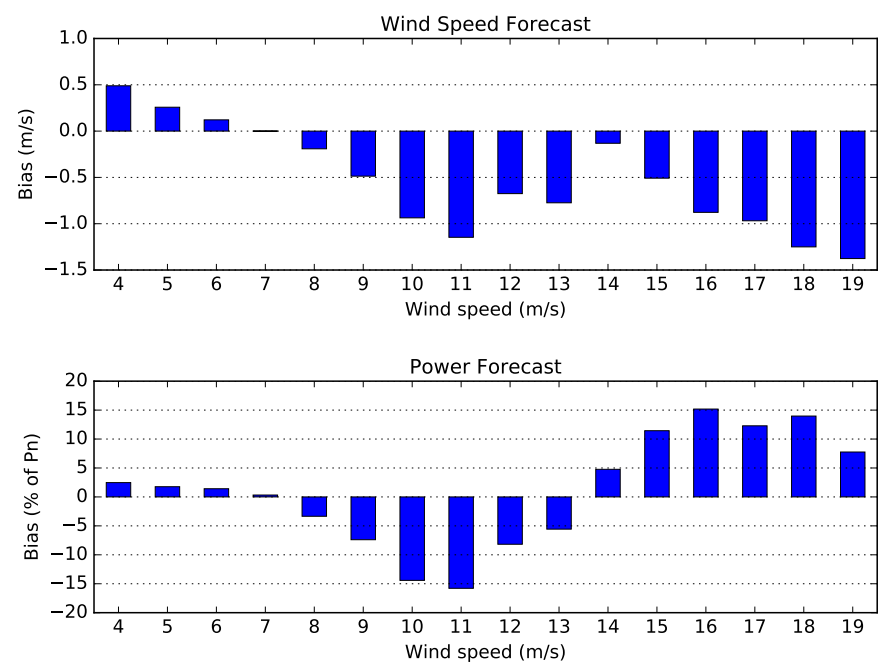

Fig. 4. Bias of wind speed (top) and power forecasts (bottom) generated by provider B for Wind Farm 1

Similar results are observable in the other forecasts, as shown in Fig. 5. Forecast $\mathrm{E}$ is, however, an exception in that it overestimates power generation at almost every wind speed. Nonetheless, the pattern of results is similar to the other forecasts, with the bias decreasing in the central region and sharply increasing at $v=14 \mathrm{~m} / \mathrm{s}$.

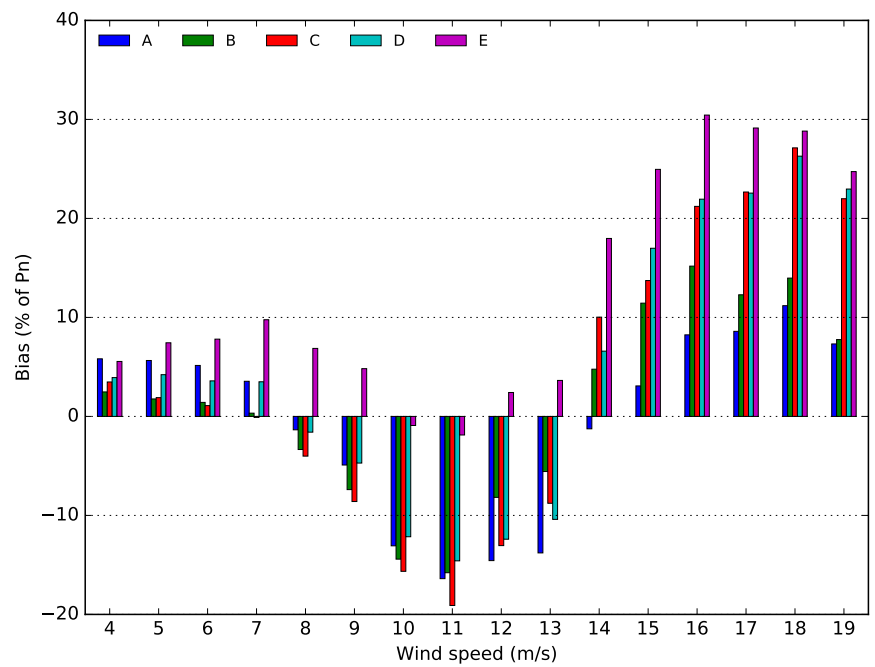

Fig. 5. Bias of power forecasts for Wind Farm 1

Results for Wind Farm 2 exhibited similar patterns to those of Wind Farm 1 described above, with systematic errors in the power curve model notably affecting power forecasting error.

\section{DISCUSSION}

From the results in Section V-A, one can see that it is not always the same forecast that performs best across the two sites. Also the rankings of the models change, with some forecasts showing a significant variation in performance depending on the wind farm. The results obtained by the best forecasters across the two wind farms are generally in line with the state-of-the-art described in Section II. In [1], the $N M A E$ values of the two wind farms located in complex terrain ranged from approximately $10 \%$ to $16 \%$ for a 24 hours horizon. In the current study, where the time horizon varies approximately from 12 to 36 hours, NMAE ranges from $10.4 \%$ to $18.5 \%$.

Forecasters used the historical measured data to train their power curve models; nevertheless, their estimation of the power curve was systematically wrong at high wind speeds. In fact, the power output at high wind speeds showed a gradual reduction over the four-year training period. Forecasters however did not capture this variation of the power curve performance over time.

The lack of feedback from the wind farm owners during the trial period was another factor that prevented the forecasters from identifying the observed systematic error at high wind speeds and, thus, from re-training and updating their models.

\section{CONCLUSIONS}

This analysis shows that inaccurate power curve estimation can have a significant effect on wind farm power forecasting error, most notably in higher wind speed ranges. In the case studies considered, we observed that the forecasters did generate empirical site-specific power curves using the training data set provided by the wind farm owners. However, their estimation showed noticeable systematic errors, in particular in the rated power region ( $v_{\text {rated }} \leq v \leq v_{\text {cut-off }}$ ).

Long-term data (four years) for the case studies indicate that power curve performances vary over time. However, wind power forecast providers did not appear to capture the observed time-dependent negative power conversion trends which were apparent from the training data set, with a resulting systematic overestimation of power output at higher wind speeds.

The results of this paper indicate that industry best practice can be improved with regard to: 1) modelling site-specific power conversion for higher wind speeds; and 2) extracting wind power conversion trends from training data. Moreover, it highlights the critical importance of continuous updating of wind farm power output curves.

\section{REFERENCES}

[1] G. Kariniotakis, I. Mart, D. Casas, P. Pinson, T. S. Nielsen, H. Madsen G. Giebel, J. Usaola, and I. Sanchez, What performance can be expected by short-term wind power prediction models depending on site characteristics?, Forecast, pp. 2225, 2004.

[2] S. Sperati, S. Alessandrini, P. Pinson, and G. Kariniotakis, The 'Wire' benchmarking exercise on short-term forecasting of renewable power forecasting, Energies, vol. 8, pp. 119, 2015.

[3] G. Giebel, R. Brownsword, G. Kariniotakis, M. Denhard, and C. Draxl, The State-Of-The-Art in Short-Term Prediction of Wind Power A Literature Overview, Tech. Report, ANEMOS.plus, pp. 1109, 2011.

[4] T. Jin and Z. Tian, Uncertainty analysis for wind energy production with dynamic power curves, 2010 IEEE 11th Int. Conf. Probabilistic Methods Appl. to Power Syst., pp. 745750, 2010.

[5] J. Collins, J. Parkes, and a. Tindal, Forecasting for utility-scale wind farms \&amp;amp;x2014; the power model challenge, 2009 CIGRE/IEEE PES Jt. Symp. Integr. Wide-Scale Renew. Resour. Into Power Deliv. Syst., pp. 247257, 2009.

[6] H. Madsen, P. Pinson, and G. Kariniotakis, Standardizing the performance evaluation of shortterm wind power prediction models, Wind Eng., vol. 29, no. 6, pp. 475489, 2005. 